\title{
Hubungan Konsumsi Camilan dan Durasi Waktu Tidur dengan Obesitas di Permukiman Padat Kelurahan Simolawang, Surabaya
}

\section{Relation between Snacking and Sleep Duration with Obesity at Slum Area Simolawang Sub-District, Surabaya}

\author{
Azizah Ajeng Pratiwi*1, Triska Susila Nindya ${ }^{1}$
}

\begin{abstract}
ABSTRAK
Latar Belakang: Obesitas pada wanita dengan status sosial ekonomi rendah banyak ditemui di permukiman padat. Rendahnya status sosial ekonomi dapat berdampak pada perubahan pola makan, seperti kebiasaan konsumsi camilan yang diketahui menjadi penyebab obesitas. Selain perubahan pola makan, perubahan gaya hidup seperti berkurangnya waktu tidur juga dapat terjadi karena kondisi lingkungan maupun tuntutan pekerjaan. Berkurangnya waktu tidur akan berdampak pada kesehatan.

Tujuan: Untuk menganalisis hubungan kebiasaan konsumsi camilan dan durasi waktu tidur dengan obesitas pada ibu rumah tangga di permukiman padat penduduk.

Metode: Penelitian ini merupakan penelitian observasional analitik dengan desain penelitian cross sectional. Sampel penelitian adalah 70 wanita yang sudah menikah berusia 20-55 tahun di Kelurahan Simolawang Kecamatan Simokerto, Surabaya. Pemilihan sampel dilakukan dengan menggunakan multistage random sampling. Pengambilan data dilakukan dengan metode wawancara menggunakan kuesioner untuk mendapatkan data karakteristik responden dan durasi waktu tidur. Food Frequency Questionnaire (FFQ) dilakukan untuk mengetahui kebiasaan konsumsi camilan. Analisis statistik dilakukan dengan menggunakan uji chi square $(\alpha=0,05)$.

Hasil: Hasil menunjukkan bahwa $54,3 \%$ responden jarang mengonsumsi camilan dan $50 \%$ responden memiliki waktu tidur yang kurang. Durasi waktu tidur memiliki hubungan yang signifikan dengan kondisi obesitas $(p=0,009)$. Selain itu kebiasaan konsumsi camilan dan obesitas juga menunjukkan adanya hubungan yang signifikan $(p=0,004)$.

Kesimpulan: Diperlukan adanya pembatasan konsumsi camilan dan tidur dengan durasi waktu cukup, yaitu 7 jam per malam untuk mencegah terjadinya obesitas.
\end{abstract}

Kata Kunci: obesitas, durasi tidur, kebiasaan camilan, permukiman padat 


\begin{abstract}
Background: Obesity in women with low socioeconomic status is easily found in slum area. Low socioeconomic status can have an impact on dietary changes, such as snacking that are known to be the cause of obesity. In addition to dietary changes, lifestyle changes such as sleep deprivation can also occur due to environmental conditions and job demands. Reduced bedtime will have an impact on health.
\end{abstract}

Objectives: The purpose of this study was to analyze the association of sleep duration and snacking to obesity.

Methods: This research was an observational analytical with cross sectional design. The sample was 70 married women aged 20-55 years in Simolawang, Simokerto Distict, Surabaya. Selection of smaple was using multistage random sampling. The data were collected by interview method with questionnaire to collect respondent characteristics data and sleep duration. Food Frequency Questionnaire (FFQ) was conducted to determine the snacking habits. Chi square test was used in the statistical analysis $(\alpha=0.05)$.

Results: The data showed that $54.3 \%$ of respondents rarely consumed snack and $50 \%$ of them had sleep less time. The sleep duration had a significant association with obesity $(p=0.009)$. In addition, snacking habits and obesity also showed a significant relationship ( $p=0.004)$.

Conclusions: It is necessary to reduce the consumption of snacks and improve sleep time which is 7 hours per night to prevent obesity.

Keywords: obesity, sleep duration, snacking, slum area

\footnotetext{
*Koresponden:

ichaajengp@hotmail.com

${ }^{1}$ Departemen Gizi Kesehatan, Fakultas

Kesehatan Masyarakat-Universitas Airlangga
} 


\section{PENDAHULUAN}

Obesitas merupakan salah satu masalah gizi dengan prevalensi yang cukup tinggi di negara berkembang seperti Indonesia. Hasil Riskesdas pada 2013 menunjukkan prevalensi obesitas pada penduduk dewasa sebesar 15,4\%. Jawa Timur menjadi salah satu provinsi diantara enam belas provinsi yang memiliki prevalensi obesitas diatas nasional yaitu sebesar $16,4 \%^{1}$. Obesitas lebih banyak terjadi pada wanita $(15,5 \%)$ bila dibandingkan dengan laki-laki $(7,8 \%)^{2}$. Obesitas pada wanita terutama ibu sangat berpengaruh jika berencana untuk memiliki anak. Ibu yang obesitas pada saat mengandung akan lebih berisiko mengalami preeklampsia ${ }^{3}$. Preeklampsia dapat menyebabkan kematian pada janin maupun ibu hamil ${ }^{4}$.

Salah satu faktor utama terjadinya peningkatan angka obesitas di negara berkembang adalah adanya globalisasi, perekonimian bebas dan urbanisasi ${ }^{5}$. Perpindahan penduduk dari pedesaan ke kota yang tidak dibarengi dengan kemampuan keterampilan kerja menimbulkan permasalahan baru yaitu susah mendapat pekerjaan dan para pendatang cenderung berkerja serabutan dengan pendapatan harian yang tidak tetap ${ }^{6}$.

Tingkat pendapatan yang rendah pada masyarakat di permukiman kumuh padat penduduk menjadi faktor pemilihan makanan modern siap saji dengan harga relatif murah. Makanan modern siap saji identik dengan kandungan gizi yang rendah serat, tinggi karbohidrat sederhana, lemak, dan gula ${ }^{7}$. Jenis makanan dengan kalori tinggi dan apabila menjadi konsumsi harian dapat menyebabkan peningkatan kejadian obesitas pada masyarakat kumuh perkotaan ${ }^{8}$. Makanan dengan densitas energi tinggi identik dengan jenis makanan yang dikonsumsi saat snacking.

Snacking (kebiasaan ngemil) akan menyebabkan tingginya asupan lemak jenuh dan total energi apabila tidak diimbangi dengan pengurangan makanan utama. Selain itu snacking dapat menyebabkan pola makan yang tidak teratur. Pola makan yang tidak teratur memiliki dampak merugikan pada thermogenesis, kadar lemak, dan profil insulin ${ }^{9}$. Pola makan yang tidak sehat dengan kebiasaan konsumsi makanan berlemak seperti pada gorengan dan camilan lebih banyak ditemui pada populasi wanita di permukiman padat penduduk ${ }^{10}$.

Tingkat pendapatan keluarga yang rendah pada penduduk permukiman padat memiliki kecenderungan bagi seseorang untuk bekerja hingga larut malam sehingga waktu tidur semakin berkurang ${ }^{11}$. Tuntutan pekerjaan, penyakit gangguan tidur, ataupun sekedar gaya hidup membuat seseorang tidur larut malam ${ }^{12}$. Waktu tidur singkat $(<6$ jam) menurut Taheri ${ }^{13}$ dapat mempengaruhi kerja hormon leptin dan ghrelin sehingga memicu munculnya rasa lapar yang dapat menyebabkan seseorang menjadi overeating.

Kelurahan Simolawang merupakan salah satu daerah permukiman padat penduduk di kawasan Surabaya Pusat dengan luas wilayah $41 \mathrm{Ha}$ dan jumlah penduduk sebanyak 23.611 orang $^{14}$. Berdasarkan hasil pemeriksaan obesitas yang dilakukan oleh Puskesmas Simolawang, angka obesitas pada wanita usia produktif di wilayah ini mencapai 1.831 orang. Tujuan penelitian ini untuk menganalisis hubungan lama waktu tidur dan konsumsi camilan dengan obesitas pada ibu rumah tangga di permukiman padat penduduk Kelurahan Simolawang, Surabaya.

\section{METODE}

Penelitian ini merupakan penelitian kuantitatif observasional analitik dengan menggunakan rancang bangun potong lintang (cross sectional). Penelitian ini dilakukan di Kelurahan Simolawang Kota Surabaya, Jawa Timur. Populasi dalam penelitian ini adalah ibu rumah tangga berusia 20-55 tahun di Kelurahan Simolawang Kota Surabaya. Pengambilan sampel dilakukan dengan cara multistages random sampling (rancangan bertingkat). Dilakukan pemilihan kelurahan dari Kecamatan Simokerto, kemudian dipilih beberapa RW secara PPS dari kelurahan terpilih sehingga didapatkan 70 orang responden.

Pengumpulan data primer meliputi usia, pendidikan terakhir, pendapatan, pekerjaan, dan lama waktu tidur di malam 
hari. Frekuensi konsumsi camilan didapatkan dengan kuesioner FFQ (Food Frequency Questionnaire) yang sebelumnya dilakukan FGD (Focus Group Discussion) untuk mendapatkan daftar makanan camilan. Data FFQ kemudian diolah dengan cara memberikan skor konsumsi rata-rata harian dari daftar camilan yang dikonsumsi. Kebiasaan konsumsi camilan dikategorikan menjadi sering dan jarang berdasarkan hasil rata-rata ${ }^{33}$. Sedangkan lama waktu tidur dikategorikan menjadi cukup ( $>6 \mathrm{jam} / \mathrm{malam}$ ) dan kurang $(\leq 6 \mathrm{jam} / \mathrm{malam})^{29}$. Pengukuran tinggi badan menggunakan mikrotoa GEA dengan tingkat akurasi 0,1 sentimeter dan berat badan diukur menggunakan Camry digital bathroom scale kapasitas 150 kilogram dengan tingkat akurasi 0,1 kilogram. Data yang terkumpul disajikan secara deskriptif menggunakan tabel frekuensi dan tabulasi silang. Uji statistik chi square dengan $\alpha=0,05$ dilakukan untuk menganalisis hubungan antar variabel penelitian.

Penelitian ini telah mendapat izin dari Komisi Etik Fakultas Kesehatan Masyarakat Universitas Airlangga Surabaya dengan nomor 188-KEPK tanggal 8 Mei 2017 serta Badan Kesatuan Bangsa dan Politik (Bakesbangpol) Kota Surabaya dengan nomor 070/4573/436.8.5/2017 tanggal 4 Mei 2017. Inform consent telah didapatkan dari masingmasing responden.

\section{HASIL DAN PEMBAHASAN}

Pada penelitian ini, responden obesitas dan tidak obesitas memiliki jumlah yang sama, yaitu 35 orang sehingga didapatkan total responden sebanyak 70 orang. Distribusi karakteristik responden tersaji dalam Tabel 1. Berdasarkan hasil wawancara diketahui bahwa sebanyak 23 responden berusia 30-39 tahun (32,9\%). Usia memiliki pengaruh terhadap metabolisme tubuh, semakin bertambahnya usia maka metabolisme akan semakin melambat. Resting Metabolic Rate (RMR) akan semakin menurun seiring dengan bertambahnya usia, sehingga otot akan mengecil apabila tidak diimbangi dengan aktivitas fisik yang cukup dan massa lemak tubuh akan meningkat ${ }^{15}$. Sebagian besar responden $(55,7 \%)$ memiliki tingkat pendidikan dasar. Kondisi ini akan berpengaruh terhadap daya terima responden terkait dengan informasi gizi. Seseorang dengan pendidikan yang lebih tinggi akan lebih mudah menerima, mengakses, dan menginterpretasikan informasi yang diperoleh. Hal ini juga berkaitan dengan informasi terkait gizi yang lebih mudah didapatkan oleh kelompok pendidikan menengah sehingga dapat memiliki praktik gizi lebih baik terutama dalam konsumsi makanan dan aktivitas fisik yang berkaitan dengan obesitas $^{16}$.

Tingkat pendapatan responden sebagian besar berada pada kuartil $1(27,1 \%)$ dan kuartil $2(27,1 \%)$. Pendapatan setiap bulan akan berpengaruh pada daya beli dan jenis makanan yang dikonsumsi sehari-hari. Seseorang dengan tingkat pendapatan yang rendah akan mengalami kesulitan untuk mendapatkan makanan dengan kandungan kalori yang rendah seperti sayur, buah dan serealia karena harganya yang relatif lebih mahal sehingga makanan dengan kandungan karbohidrat dan lemak yang memiliki harga lebih murah menjadi pilihan responden pada tingkat pendapatan rendah untuk dikonsumsi ${ }^{17}$. Mayoritas responden (65,7\%) memiliki pekerjaan sehari-sehari sebagai ibu rumah tangga. Aktivitas fisik yang rendah dalam lingkungan rumah tangga menjadi salah satu faktor risiko terjadinya obesitas pada ibu rumah tangga ${ }^{18}$. Kegiatan rumah tangga yang dilakukan dan menjadi rutinitas setiap hari juga dapat menjadikan ibu rumah tangga tidak sempat melakukan olahraga ${ }^{18}$.

Tabel 2 menunjukkan bahwa frekuensi konsumsi camilan tertinggi sebanyak 7 kali per hari dan terendah sebanyak 0,03 kali per hari. Median dari konsumsi camilan responden adalah sebanyak 1 kali per hari. Sedangkan durasi tidur terlama responden adalah selama 11 jam per malam dan durasi tidur tersingkat selama 3 jam per malam. 
Tabel 1. Distribusi Karakteristik Ibu Rumah Tangga di Kelurahan Simolawang, Surabaya

\begin{tabular}{lrrrrrr}
\hline \multicolumn{1}{c}{ Variabel } & \multicolumn{2}{c}{ Obesitas } & \multicolumn{2}{c}{ Tidak Obesitas } & \multicolumn{2}{c}{ Total } \\
\cline { 2 - 7 } & $\mathbf{n}$ & $\mathbf{\%}$ & $\mathbf{n}$ & $\mathbf{\%}$ & $\mathbf{N}$ & $\%$ \\
\hline Kelompok Usia & & & & & & \\
$\quad$ 20-29 tahun & 4 & 11,4 & 10 & 28,6 & 14 & 20,0 \\
30-39 tahun & 12 & 34,3 & 11 & 31,4 & 23 & 32,9 \\
$\quad$ 40-49 tahun & 11 & 31,4 & 9 & 25,7 & 20 & 28,6 \\
$\quad$ 250 tahun & 8 & 22,9 & 5 & 14,3 & 13 & 18,5 \\
Tingkat Pendidikan & & & & & & \\
$\quad$ Dasar & 23 & 65,7 & 16 & 45,7 & 39 & 55,7 \\
$\quad$ Menengah & 10 & 28,6 & 17 & 48,6 & 27 & 38,6 \\
$\quad$ Tinggi & 2 & 5,7 & 2 & 5,7 & 4 & 5,7 \\
Pendapatan & & & & & & \\
$\quad$ Kuartil 1 & 11 & 31,4 & 6 & 17,2 & 17 & 24,3 \\
$\quad$ Kuartil 2 & 8 & 22,9 & 11 & 31,4 & 19 & 27,1 \\
$\quad$ Kuartil 3 & 10 & 28,6 & 9 & 25,7 & 19 & 27,1 \\
$\quad$ Kuartil 4 & 6 & 17,1 & 9 & 25,7 & 15 & 21,5 \\
Pekerjaan & & & & & & \\
$\quad$ Ibu rumah tangga & 24 & 68,5 & 22 & 62,9 & 46 & 65,7 \\
$\quad$ Berdagang & 9 & 25,7 & 9 & 25,7 & 18 & 25,7 \\
$\quad$ Asisten rumah tangga & 1 & 2,9 & 0 & 0,0 & 1 & 1,4 \\
$\quad$ Swasta & 1 & 2,9 & 4 & 11,4 & 5 & 7,2 \\
\hline
\end{tabular}

Tabel 2. Sebaran Data Frekuensi Konsumsi Camilan dan Lama Waktu Tidur di Kelurahan Simolawang, Surabaya

\begin{tabular}{lccc}
\hline \multicolumn{1}{c}{ Variabel } & Minimal & Maksimal & Median \\
\hline Frekuensi Konsumsi Camilan (kali/hari) & 0,03 & 7,00 & 1,00 \\
Lama Waktu Tidur (jam/malam) & 3,00 & 11,00 & 6,25 \\
\hline
\end{tabular}

Tabel 3. Hubungan Kebiasaan Konsumsi Camilan dan Durasi Waktu Tidur dengan Obesitas di Kelurahan Simolawang, Surabaya

\begin{tabular}{|c|c|c|c|c|c|c|c|}
\hline \multirow{2}{*}{ Variabel } & \multicolumn{2}{|c|}{ Obesitas } & \multicolumn{2}{|c|}{ Tidak Obesitas } & \multicolumn{2}{|c|}{ Total } & \multirow{2}{*}{ P-value } \\
\hline & $\mathrm{n}$ & $\%$ & $\mathbf{n}$ & $\%$ & $\mathbf{N}$ & $\%$ & \\
\hline \multicolumn{8}{|l|}{ Kebiasaan Konsumsi Camilan } \\
\hline Sering ( $\geq$ mean) & 22 & 63 & 10 & 29 & 32 & 45,7 & 0,004 \\
\hline Jarang (< mean) & 13 & 37 & 25 & 71 & 38 & 54,3 & \\
\hline \multicolumn{8}{|l|}{ Lama Waktu Tidur } \\
\hline Cukup (> 6 jam/malam) & 12 & 34 & 23 & 66 & 35 & 50 & 0,009 \\
\hline Kurang ( $\leq 6 \mathrm{jam} /$ malam) & 23 & 66 & 12 & 34 & 35 & 50 & \\
\hline
\end{tabular}

Median dari lama waktu tidur responden adalah selama 6,25 jam per malam. Kebiasaan konsumsi camilan memiliki hubungan yang signifikan dengan obesitas berdasarkan hasil uji statistik chi square (Tabel 3). Kebiasaan konsumsi camilan dapat menjadi salah satu penyumbang asupan energi. Menurut McCrory dan Campbell ${ }^{19}$ terlepas dari jenis camilan yang dikonsumsi, mengkonsumsi makanan ringan atau camilan dalam frekuensi yang sering dapat menyebabkan asupan makanan berlebih dan berpotensi mengalami kenaikan berat badan. Jumlah camilan yang dikonsumsi memang 
cenderung lebih sedikit bila dibandingkan dengan jumlah pada menu utama, namun frekuensi camilan yang sering dapat menjadikan jumlah kalori yang dikonsumsi setara dengan saat konsumsi menu utama $^{20}$. Kebiasaan konsumsi camilan juga dapat menjadikan seseorang melewatkan waktu makan utama ${ }^{21}$.

Pemilihan jenis makanan, waktu, dan frekuensi konsumsi camilan menjadi sangat berpengaruh pada tingkat asupan energi dan peningkatan berat badan ${ }^{22}$. Sebagian besar responden memiliki jenis makanan camilan yang sama, yaitu gorengan seperti tahu isi, lumpia, dan bakwan. Jenis makanan camilan yang mengandung lemak dan makanan manis berkontribusi dalam peningkatan asupan energi sehingga dapat menimbulkan peningkatan berat badan ${ }^{23}$. Peningkatan berat badan juga dapat dikarenakan tidak adanya pengurangan jumlah makanan yang dikonsumsi pada saat waktu makan utama. Waktu snacking responden sebagian besar berdekatan dengan waktu makan utama, yaitu makan siang dan makan malam/sore. Jumlah porsi makan responden pun tidak berkurang saat makan utama walaupun beberapa waktu sebelumnya responden sudah mengkonsumsi jajanan.

Hasil penelitian ini sejalan dengan penelitian yang dilakukan oleh Guerrero, $\mathbf{d k k}^{24}$ di Spanyol yang menyatakan bahwa snacking berhubungan dengan obesitas pada wanita, yaitu wanita dengan kebiasaan snacking memiliki risiko mengalami obesitas 1,53 lebih besar bila dibandingkan dengan laki-laki. Penelitian lain oleh Forslund, $\mathbf{d k k}^{25}$ yang dilakukan di Swedia menyatakan bahwa makan camilan berhubungan positif dengan tingkat asupan energi.

Hasil penelitian ini juga menunjukkan bahwa terdapat hubungan signifikan antara durasi waktu tidur yang singkat dengan obesitas berdasarkan uji statistik chi square (Tabel 3). Kurangnya waktu tidur pada responden dikarenakan banyaknya kegiatan rumah tangga yang harus dilakukan sejak dini hari, seperti mencuci baju, memasak, dan menunggu pasokan air bersih untuk kegiatan sehari- hari. Kondisi ini yang menyebabkan durasi waktu tidur pada ibu rumah tangga menjadi berkurang. Waktu tidur yang kurang dapat menyebabkan peningkatan produksi hormon kortisol dan peningkatan sekresi insulin ${ }^{26}$. Salah satu fungsi dasar insulin adalah menghambat terjadinya lipolisis pada sel adiposa ${ }^{27}$. Jika jumlah hormon insulin dalam tubuh meningkat, maka pemechan sel lemak menjadi semakin terhambat dan dapat meningkatkan profil lipid dalam tubuh. Selain menghambat lipolisis, hormon insulin juga dapat menjadi promotor penyimpanan trigliserida dengan menurunkan transkripsi lipase trigliserida dalam jaringan adiposa ${ }^{28}$. Mekanisme ini dapat meningkatkan lemak tubuh dan menyebabkan obesitas.

Selain terjadi perubahan pada kadar hormon insulin tubuh, durasi tidur singkat juga dapat mempengaruhi hormon leptin dan ghrelin yang menjadi regulator rasa lapar. Berkurangnya waktu tidur dapat meningkatkan hormon ghrelin yang menjadi promotor rasa lapar. Peningkatan hormon ghrelin akan dibarengi dengan penurunan kadar hormon leptin, dimana hormon leptin diketahui menjadi hormon yang berpengaruh pada timbulnya rasa kenyang ${ }^{13}$. Dengan adanya peningkatan hormon ghrelin pada individu dengan durasi tidur singkat, maka akan terjadi peningkatan nafsu makan. Hal ini juga berkaitan dengan kebiasaan konsumsi camilan pada responden obesitas yang lebih tinggi bila dibandingkan dengan responden tidak obesitas (Tabel 3). Kebiasaan konsumsi camilan yang tinggi juga mungkin terjadi karena responden obesitas lebih banyak yang memiliki waktu tidur singkat sehingga memicu peningkatan hormon ghrelin dan menyebabkan timbulnya rasa lapar.

Selain itu kurangnya waktu tidur juga berdampak pada keseimbangan energi. Hormon leptin yang menurun 
diketahui dapat menurunkan tingkat pengeluaran energi, karena dengan adanya hormon leptin dapat meningkatkan pengeluaran energi ${ }^{28}$. Hasil penelitian ini sejalan dengan hasil penelitian yang dilakukan oleh Anic, dkk ${ }^{29}$ pada wanita yang obesitas memiliki waktu tidur yang kurang dari 6 jam saat malam hari. Selain itu penelitian lain mengenai obesitas pada wanita di permukiman kumuh yang dilakukan oleh Anuradha, $\mathrm{dkk}^{30}$ di India juga menunjukkan hasil serupa. Penelitian yang dilakukan oleh Morselli, dkk ${ }^{31}$ menyatakan bahwa durasi tidur singkat dapat menstimulasi asupan makanan hingga $>250 \mathrm{kkal} / \mathrm{hari}$. Studi meta analisis yang dilakukan oleh $\mathrm{Wu}$, $\mathrm{dkk}^{32}$ menyatakan bahwa waktu tidur singkat berhubungan signifikan dengan insiden obesitas pada orang dewasa.

Keterbatasan dalam penelitian ini adalah tidak dapat ditampilkannya angka risiko terkait pengaruh kebiasaan konsumsi camilan dan durasi waktu tidur dengan obesitas. Hal ini dikarenakan desain penelitian yang digunakan, yaitu cross sectional. Penelitian ini tidak mengelompokkan atau membedakan antara kelompok terpapar dan outcome yang dihasilkan.

\section{KESIMPULAN}

Penelitian ini memberikan kesimpulan bahwa seringnya konsumsi camilan dan durasi waktu tidur malam yang singkat/kurang dapat menjadi penyebab terjadinya obesitas pada ibu rumah tangga di permukiman padat penduduk Kelurahan Simolawang, Surabaya. Pembatasan atau pengurangan jumlah konsumsi camilan perlu dilakukan untuk mencegah peningkatan berat badan yang dapat menyebabkan obesitas. Selain itu tidur dengan durasi waktu yang cukup (7 jam per malam) dapat dilakukan untuk menurunkan risiko obesitas.

\section{ACKNOWLEDGEMENT}

Terima kasih dan penghargaan diberikan penulis kepada seluruh staf pengajar program studi ilmu gizi Universitas Airlangga atas bimbingan dan dukungan yang telah diberikan. Ucapan terima kasih dan penghargaan juga diberikan penulis kepada seluruh responden yang terlibat dalam penelitian, Puskesmas Simolawang, dan para kader di setiap RW yang terlibat penelitian.

\section{REFERENSI}

1. Kementerian Kesehatan RI. Riset Kesehatan Dasar. 2013

2. Kementerian Kesehatan RI. Riset Kesehatan Dasar. 2010.

3. Wafiyatunisa Z, Rodiani. Hubungan Obesitas dengan Terjadinya Preeklampsia. Majority 2016; 5(5): 184190

4. Dumais CEG, Lengkong RA, Mewengkang ME. Hubungan Obesitas pada Kehamilan dengan Preeklampsia. Jurnal e-Clinic 2016; 4(1).

5. Popkin, BM, Adair LS, Ng SW. Now and Then: The Global Nutrition Transition: The Pandemic of Obesity in Developing Countries. Nutrition Reviews 2012; 70(1): 3-21.

6. Deepika V, Pallavi S, Subita P, Balkrishna A, Ramesh C. A Study of Select Epidemiological Factors Associated with Obesity in Women above 20 Years of Age in an Urban Slum Area. International Journal of Medical and Health Research 2015; 1(3): 74-80.

7. Ziraba Ak, Fosto JC, Ochako R. Overweight and Obesity in Urban Africa: A problem of the Rich or the Poor?. BMC Public Health 2009; 9: 465.

8. American Institute for Cancer Research. Food, Nutrition, Physical Activity, and the Prevention of Cancer: A Global Perspective. Available from http://www.aicr.org/assets/docs/pdf/rep orts/Second_Expert_Report.pdf. Diakses pada 18 Juli 2017. 
9. Farshchi HR, Taylor MA, Macdonald IA. Beneficial Metabolic Effects of Regular Meal Frequency on Dietary Thermogenesis, Insulin Sensitivity, and Fasting Lipid Profiles in Healthy Obese Women. American Journal Clinical Nutrition 2005; 81: 16 -24.

10. Yulia, Khusun $H$, Fahmida U. Dietary Patterns of Obese and Normal-Weight Women of Reproductive Age in Urban Slum Areas in Central Jakarta. British Journal Nutrition 2016; 1: 49-56.

11. Jaaskelainen A, Nevanpera $N$, Remes J, Rahkonen F, Jarvelin MR, Laitinen J. Stress-Related Eating, Obesity and Associated Behavioural Traits in Adolescents: A Prospective PopulationBased Cohort Study. BMC Public Health 2014; 14(321): 114.

12. Prio PA. Durasi Tidur Singkat dan Obesitas. J Majority 2015; 4(6): 5-9.

13. Taheri $S$, Lin L, Austin $D$, Young $T$, Mignot E. Short Sleep Duration is Associated with Reduce Leptin, Elevated Ghrelin, and Increased Body Mass Index. Plos Medicine 2004; 1(3): 210-217.

14. Pemerintah Kota Surabaya. Profil Kelurahan Simolawang, Kecamatan Simokerto. 475/10/436.10.19/2017.

15. Nurzakiah N, Echadi E, Sartika RA. Faktor Risiko Obesitas pada Orang Dewasa Urban dan Rural. Jurnal Kesehatan Masyarakat Nasional 2010; 5(1): 29-34.

16. Diana R, Yuliana I, Yasmin G, Hardinsyah. Faktor Risiko Kegemukan pada Wanita Dewasa Indonesia. Jurnal Gizi dan Pangan 2013; 8(1): 1-8.

17. Novitasary MD, Mayulu N, Kawengian SES. Hubungan antara Aktivitas Fisik dengan Obesitas oada Wanita Usia Subur Peserta Jamkesmas di Puskesmas Wawonasa Kecamatan Singkil Manado. Jurnal e-Biomedik 2013; 1(2): 1040-1046.

18. Saboo B, Talaviya P, Chandarana H, Shah $\mathrm{S}$, Vyas C, Nayak H. Prevalence of Obesity and Overweight in Housewives and its Relation with Household Activities and Socio-Economical Status. Journal of Obesity and Metabolic Research 2014; 1(1): 20-24.
19. McCrory MA, Campbell WW. Effects of Eating Frequency, Snacking, and Breakfast Skipping on Energy Regulation: Symposium Overview. The Journal of Nutrition 2011; 141: 144-147.

20. Mills JP, Perry CD, Reicks M. Eating Frequency is Associated with Energy Intake but not Obesity in Midlife Women. Obesity 2011; 19(3): 552-559.

21. Sanchez-Villegas A, Martinez-Gonzalez MA, Toledo E, de Irala-Estevez J, Martinez JA. Relative Role of Physical Inactivity and Snacking between Meals in Weight Gain. Medicina Clinica 2002; 119(2): 46-52.

22. Kong A, Beresford SAA, Alfano CM, Foster-Schubert KE, Neuhouser ML, Johnson DB, Duggan C, Wang CY, Xiao L, Bain CE, McTiernan A. Associations between Snacking and Weight Loss and Nutrient Intake among Postmenopausal Overweight-To-Obese Women in a Dietary Weight Loss Intervention. Journal American Diet Association 2011; 111(12): pp.1898-1903.

23. Forslund $H B$, Lindroos $A K$, Sjostrom $L$, Lissner L. Meal Patterns and Obesity in Swedish Women-A Simple Instrument Describing Usual Meal Types, Frequency and Temporal Distribution. European Journal of Clinical Nutrition 2002; 56: 740-747.

24. Guerrero RT, Paulino YC, Novotny R, Murphy SP. Diet and obesity among Chamorro and Filipino adults on Guam. Asia Pacific Journal Clinical Nutrition 2008; 17(2): 216-222.

25. Harvard Medical School. Sleep and Disease Risk. Harvard Medical School: Division of Sleep Medicine. 2007. Available from http://healthysleep.med.harvard.edu/he althy/matters/consequences/sleep-anddisease-risk. Diakses pada 15 Juli 2010.

26. Morigny $P$, Houssier $M$, Mouisel $E$, Langin D. Adipocyte Lipolysis and Insulin Resistance. Biochimie 2016; 125: 259266.

27. Chakrabarti $P$, Kim JY, Singh $M$, Sin $Y$, Kim J, Kumbrink J, Wu Y, Lee $M$, Kirsch $\mathrm{KH}$, Fried SK, Kandror KV. Insulin Inhibits Lipolysis in Adipocytes via the 
Evolutionarily Conserved mTORC1-Egr1ATGL-Mediated Pathway. Molecular and Cellular Biology 2013; 33(18): 3659-3666.

28. Beccuti G, Pannain S. Sleep and Obesity. Current Opinion Clinical Nutrition Metabolic Care 2011; 14(4): 402-412.

29. Anic GM, Titus-Ernstoff L, Newcomb PA, Trentham-Dietz A, Egan KM. Sleep Duration and Obesity in a PopulationBased Study. Sleep Medicine 2010; 11(5): 447-451.

30. Anuradha R, Ravivarman G, Jain T. The Prevalence of Overweight and Obesity among Woman in an Urban Slum of Chennai. Journal of Clinical and Diagnostic Research 2011; 5(5): 957-960.
31. Morselli LL, Guyon A, Spiegel K. Sleep and Metabolic Function. Pflugers Archiv European Journal of Physiology 2012; 463(1): 139-160.

32. Wu Y, Zhai L, Zhang D. Sleep Duration and Obesity among Adults: A Meta-Analysis Prospective Studies. Sleep Medicine 2014; 15(12): 1456-62.

33. Anastasia, Devi L. Frekuensi Konsumsi Bahan Makanan Sumber Kalsium pada Remaja di Tiga Sekolah Menengah Pertama di Depok Tahun 2008. Skripsi. Depok: Fakultas Kesehatan Masyarakat Universitas Airlangga, 2008. p. 42-43. 